\title{
Desidratação osmótica de fatias de jaca ${ }^{1}$
}

\author{
Osmotic dehydration of jack fruit slices
}

\section{Maria Elita Martins Duarte ${ }^{2 *}$, Sânia Mara Pereira Ugulino ${ }^{3}$, Mario Eduardo Rangel Moreira Cavalcanti Mata ${ }^{3}$, Deyzi Santos Gouveia ${ }^{4}$ e Alexandre José de Melo Queiroz ${ }^{3}$}

\begin{abstract}
RESUMO - O presente trabalho foi realizado com o objetivo de estudar a cinética e modelagem do processo de desidratação osmótica de fatias de jaca em geometria plana. $\mathrm{O}$ tratamento osmótico foi conduzido a $43{ }^{\circ} \mathrm{C}$, com agitação, utilizando-se de soluções de sacarose, nas concentrações de 40 e $50{ }^{\circ}$ Brix. O estudo da cinética de desidratação osmótica mostrou que na solução de sacarose a $50{ }^{\circ}$ Brix o valor da perda de água (WL) foi maior ao final de 28,5 horas de processo $(68,5 \%$ b.u para $40,2 \%$ b.u.), ligeiramente superior ao encontrado para a solução de sacarose a $40{ }^{\circ}$ Brix, $(68,5 \%$ b.u para $43 \%$ b.u. $)$. Comportamento contrário ocorreu para o ganho de sólidos (SG). O ajuste dos dados experimentais foi realizado através dos modelos de Page e Fick. Pela análise da equação de Fick, verificou-se que os coeficientes de difusividade efetiva foram 0,5837 e $0,6677 \mathrm{~mm}^{2} \mathrm{~min}^{-1}$ para 40 e $50{ }^{\circ}$ Brix, respectivamente.
\end{abstract}

Palavras-chave: Frutas. Desidratação. Regulação osmótica. Processamento.

\begin{abstract}
The present work was undertaken with the objective of studying the kinetics and the osmotic-dehydration modeling of slices of jack-fruit in a flat layout. The osmotic treatment was carried out at $43^{\circ} \mathrm{C}$, employing agitation, and using sucrose solutions at concentrations of $40^{\circ}$ and $50^{\circ}$ Brix. The study of the kinetics of osmotic dehydration showed that in the sucrose solution at $50^{\circ}$ Brix, the value of the water-loss (WL) was higher after 28.5 hours of processing $(68.5 \% \mathrm{wb}$ to $40.2 \% \mathrm{wb})$, slightly higher than that found for the sucrose solution at $40^{\circ}$ Brix (68.5\% wb to $43 \% \mathrm{wb}$ ). The opposite behavior was observed for the gain in solids (SG). Adjustment of the experimental data was done using the Page and Fick models. From the analysis of the Fick equation, it was found that the effective diffusivity coefficients were 0.5837 and $0.6677 \mathrm{~mm}^{2} \mathrm{~min}^{-1}$ for $40^{\circ}$ and $50^{\circ}$ Brix, respectively.
\end{abstract}

Key words: Fruits. Dehydration. Osmotic regulation. Processing.

\footnotetext{
* Autor para correspondência

Recebido para publicação em 12/04/2011; aprovado em 05/03/2012

Parte da Dissertação de Mestrado do segundo autor, apresentada ao Programa de Pós-Graduação em Engenharia Agrícola DEAg/CTRN/UFCG

2Área de Armazenamento e Processamento de Produtos Agrícolas/DEAG/CTRN/UFCG, Campus de Campina Grande, Av. Aprígio Veloso, 882, Bodocongó-PB, Brasil, 58.429-140, elita@ deag.ufcg.edu.br

${ }^{3}$ Área de Armazenamento e Processamento de Produtos Agrícolas/DEAG/CTRN/UFCG, Campus de Campina Grande-PB, Brasil, saniampu@ hotmail.com,mmata@deag.ufcg.edu.br, alex@deag.ufcg.edu.br

${ }^{4}$ Programa de Pós-Graduação em Engenharia de Processos/CCT/UFCG, Campina Grande-PB, Brasil, deyzigouveia@ yahoo.com.br
} 


\section{INTRODUÇÃO}

A desidratação osmótica é reconhecida como sendo um método de desidratação parcial energicamente econômico, uma vez que não há necessidade de uma mudança de fase. Assim, este pré-tratamento pode apresentar, nas fases iniciais da desidratação, uma taxa mais elevada de perda da água do que a taxa fornecida por processos de secagem, podendo ser usada para redução do tempo de secagem e consequente diminuição das perdas de nutrientes pelo calor (RODRIGUES; FERNANDES, 2007). Considerando os fatores citados, é possível afirmar que a desidratação osmótica é uma alternativa para o aproveitamento do excesso de produção, além de possibilitar o consumo do produto nos períodos de entressafra, desde que a técnica seja adaptada ao uso em processamento em pequena escala. Portanto, o tratamento osmótico tem se apresentado como ferramenta tecnológica importante para se desenvolver novos produtos derivados de frutas, com valor agregado e propriedades funcionais (CORREA et al., 2008; SILVEIRA, 2002; TORREGGIANI; BERTOLO, 2001).

Durante o processo de desidratação por osmose, observam-se, basicamente, as seguintes transferências de massa: saída de água do produto para a solução hipertônica e saída de soluto da solução para o produto (QUEIROZ et al., 2010). A taxa de perda de água durante a desidratação osmótica sofre a influência dos seguintes fatores: características do tecido vegetal, tipo e concentração do agente desidratante, temperatura, tempo de imersão, proporção fruta/solução e agitação (BORIN et al., 2008; RASTOGI; RAGHAVARAO, 2004; SILVA et al., 2008).

Adesidratação osmótica reduz a quantidade de água no alimento e incorpora outros sólidos, sem necessidade de energia térmica para promover a transferência de massa, como ocorre em outros processos de desidratação. O processo tem ainda como outras vantagens a inibição do escurecimento enzimático, conservação da cor natural do produto sem adição do sulfito, alta retenção de compostos voláteis durante uma desidratação posterior com ar quente (DIONELLO et al., 2009; FIOREZE, 2004), padronização do conteúdo de sólidos solúveis e, por conseguinte, a uniformidade do produto quanto a textura.

A jaca é uma fruta sazonal e seu consumo in natura é realizado nos meses de janeiro a abril, no nordeste, razão pela qual nos meses subsequentes este fruto só pode ser consumido se for empregadas tecnologias que preserve ou transforme o produto para consumo. Como a preservação, após a colheita, só é possível por um curto período devido a sua fisiologia, se faz necessário o emprego de tecnologia de processamento dessas frutas. Sendo assim, este trabalho foi realizado com o objetivo de estudar e modelar o processo de desidratação osmótica de fatias de jaca em geometria plana.

\section{MATERIAL E MÉTODOS}

Inicialmente foi realizada uma caracterização físico-química da fruta quanto aos açúcares redutores, açúcares totais, açúcares não redutores, acidez total, teor de água, $\mathrm{pH}$ e sólidos solúveis segundo a metodologia do Instituto Adolfo Lutz (2008) e teor de cinzas segundo a metodologia proposta pela Association of Official Analytical Chemists (2005).

Nos experimentos foram utilizadas jacas (Artocarpus heterophyllus) variedade dura, com estádio de maturação madura, cujo despolpamento foi realizado manualmente. A geometria adotada para a realização dos cortes foi de placa plana $(28,80 \mathrm{~mm}$ x $28,70 \mathrm{~mm})$ cuja espessura média foi de $5,80 \mathrm{~mm}$. As frutas fatiadas foram colocadas em soluções de sacarose nas concentrações de 40 e 50 Brix, respectivamente, para incorporação de açúcar. A desidratação osmótica ocorreu na proporção 1:4 (massa/ massa), ou seja, cada quilograma de fruta foi submersa em 4 quilogramas de solução, em que as concentrações de 40 e $50{ }^{\circ}$ Brix eram monitoradas, com auxílio de um refratômetro, e corrigidas sempre que necessário.

Para facilitar a dissolução, depois de colocar a fruta no xarope, manteve-se o processo sob aquecimento a $43{ }^{\circ} \mathrm{C}$.

Acompanhou-se a massa da fruta periodicamente, em intervalos de $0 ; 15 ; 30 ; 45 ; 75 ; 120 ; 180 ; 270 ; 390$; $540 ; 720 ; 930 ; 1.170 ; 1.710$ minutos, totalizando 28,5 horas de osmose momento em que se obteve o equilíbrio para ambas as condições. O acompanhamento do teor de água foi feito por meio do método padrão, utilizando-se a estufa a $105{ }^{\circ} \mathrm{C} \pm 3{ }^{\circ} \mathrm{C}$, até peso constante, segundo o Instituto Adolfo Lutz (2008). Todas as determinações foram feitas em triplicatas.

O ganho de soluto foi acompanhado, determinandose a matéria seca. Amostras da jaca eram retiradas nos intervalos estabelecidos e, em seguida, levadas para estufa, a $105^{\circ} \mathrm{C}$, até peso constante.

A cinética de desidratação foi estudada pelo acompanhamento da perda de água (PA) e ganho de sólidos ( $\mathrm{SG})$.

A perda de água foi calculada pela Equação 1:

$\operatorname{PA}(\%)=100\left[\frac{\left(\mathrm{m}_{0} \mathrm{X}_{0}-\mathrm{m}_{\mathrm{f}} \mathrm{X}_{\mathrm{f}}\right)}{\mathrm{m}_{0}}\right]$

em que:

$\mathrm{PA}=$ perda de água percentual do produto desidratado $(\%)$ 
${ }_{0}=$ massa inicial do produto $(\mathrm{g})$;

$\mathrm{f}=$ massa final do produto $(\mathrm{g})$;

$\mathrm{i}=$ teor de água inicial do produto $(\%)$;

$\mathrm{X}_{\mathrm{f}}=$ teor de água final do produto (\%).

O ganho de sólidos (SG) foi calculado utilizandose a Equação 2:

$$
S G(\%)=100\left[\frac{\left(m s_{t}-m s_{0}\right)}{m_{0}}\right]
$$

em que:

$\mathrm{SG}=$ ganho de sólidos em relação à massa inicial do produto $(\%)$;

${ }_{0}=$ massa seca inicial $(\mathrm{g})$;

${ }_{\mathrm{t}}=$ massa seca em um dado tempo $(\mathrm{g})$;

$\mathrm{m}_{0}=$ massa de produto no tempo inicial $(\mathrm{g})$.

Para estudar a cinética de desidratação osmótica, utilizou-se a Equação de Page (3) e o modelo de Fick (Equação 4).

$$
R X=\frac{X_{t}-X_{e}}{X_{0}-X_{e}}=\exp \left(K t^{n}\right)
$$

em que:

$\mathrm{X}_{\mathrm{t}}=$ teor de água médio no tempo $\mathrm{t}$, decimal (base seca);

$\mathrm{X}_{\mathrm{e}}=$ teor de água de equilíbrio, decimal (base seca);

$\mathrm{X}_{0}=$ teor de água inicial, decimal (base seca);

$\mathrm{K}, \mathrm{n}=$ parâmetros da equação de Page, adimensional;

$\mathrm{t}=$ tempo $(\mathrm{h})$.

Dando continuidade ao estudo da cinética de desidratação osmótica, fez-se uso, também, da Teoria difusional, a qual se baseia na equação da difusão líquida (Segunda Lei de Fick), onde o fluxo de massa é proporcional ao gradiente de concentração dentro do sólido. Crank (1975) propôs uma solução analítica para a Lei de Fick, considerando distribuição do teor de água inicial uniforme e ausência de qualquer resistência térmica para uma placa plana infinita (Equação 4):

$$
\begin{aligned}
& \frac{X_{t}-X_{e}}{X_{0}-X_{e}}=\frac{8}{\pi^{2}} \sum_{t=0}^{\infty} \frac{1}{(2 i+1)^{2}} \exp \left[-(2 i+1)^{2} \pi^{2} D_{e f} \frac{t}{4 L^{2}}\right] \\
& \quad \text { em que: } \\
& \mathrm{D}_{\text {ef }}=\text { difusividade efetiva }\left(\mathrm{m}^{2} \cdot \mathrm{s}^{-1}\right) ;
\end{aligned}
$$

$\mathrm{t}=$ tempo $(\mathrm{s})$;

$\mathrm{L}=$ dimensão característica (meia espessura da placa).

A difusividade referente ao processo é calculada fazendo-se uma média aritmética dos valores de difusividade encontrados para cada tempo (Equação 5):

$$
D_{e f}=\frac{\sum_{i=1}^{\infty} D_{e f(i)}}{N}
$$

em que:

$\mathrm{D}_{\mathrm{ef}}=$ difusividade efetiva média (mm2 s-1);

$\mathrm{D}_{\mathrm{ef}}$ (i) = difusividades efetivas para cada tempo (mm2 s-1);

$\mathrm{N}=$ número de pontos experimentais utilizados para o cálculo.

O erro relativo médio $(\mathrm{P})$ foi calculado utilizandose a Equação 6, com a finalidade de avaliar se os modelos utilizados descrevem satisfatoriamente os dados experimentais $(\mathrm{P}<10 \%)$.

$P=\frac{100}{N} \sum_{i=1}^{N} \frac{\left|V_{P}-V_{0}\right|}{V_{0}}$

em que,

$\mathrm{P}=$ desvio relativo médio $(\%)$;

$\mathrm{V}_{\mathrm{P}}=$ valores preditos pelo modelo;

$\mathrm{V}_{0}=$ valores observados experimentalmente;

$\mathrm{N}=$ número de pontos experimentais.

\section{RESULTADOS E DISCUSSÃO}

Na Tabela 1 encontra-se a caracterização físicoquímica da jaca dura in natura.

Comparando o resultado do teor de água, na Tabela 1, com os resultados obtidos por Langarica (2003) que encontrou teor de água inicial de 78,90\%, em seu estudo com desidratação osmótica de polpa de jaca, e por Silveira (2002), 80,43\%, também para o mesmo produto, observa-se que valor o médio deste trabalho é ligeiramente inferior aos encontrados na literatura. $\mathrm{O}$ valor de 4,7 para $\mathrm{pH}$ foi o mesmo e o valor dos sólidos solúveis muito próximo do encontrado por Langarica (2003).

Na Figura 1 encontram-se os valores experimentais do teor de água, em termos adimensionais, em função do tempo, para as duas concentrações de sacarose, 40 e $50{ }^{\circ}$ Brix, utilizadas para secagem osmótica e as curvas estimadas pela Equação de Page. Constata-se nessa figura que para as duas soluções estudadas a perda de 
Tabela 1 - Valores médios das características físico-químicas da jaca "in natura"

\begin{tabular}{lc}
\hline \multicolumn{1}{c}{ Constituinte } & Valor com SD \\
\hline Açúcares redutores (\%glicose) & $1,816 \pm 0,111$ \\
Açúcares totais (\%) & $11,569 \pm 0,552$ \\
Açúcares não redutores (\%) & $9,752 \pm 0,455$ \\
Acidez total (\% ácido cítrico) & $0,147 \pm 0,004$ \\
Teor de água (\%) & $66,010 \pm 0,185$ \\
Cinzas (\%) & $0,450 \pm 0,034$ \\
pH & $4,700 \pm 0,020$ \\
Sólidos solúveis $\left({ }^{\circ}\right.$ Brix) & $26,000 \pm 0,872$ \\
\hline
\end{tabular}

SD - Desvio padrão

Figura 1 - Dados experimentais de desidratação osmótica de jaca, em solução de sacarose a 40 e $50^{\circ}$ Brix, respectivamente, e curvas estimadas segundo a equação de Page

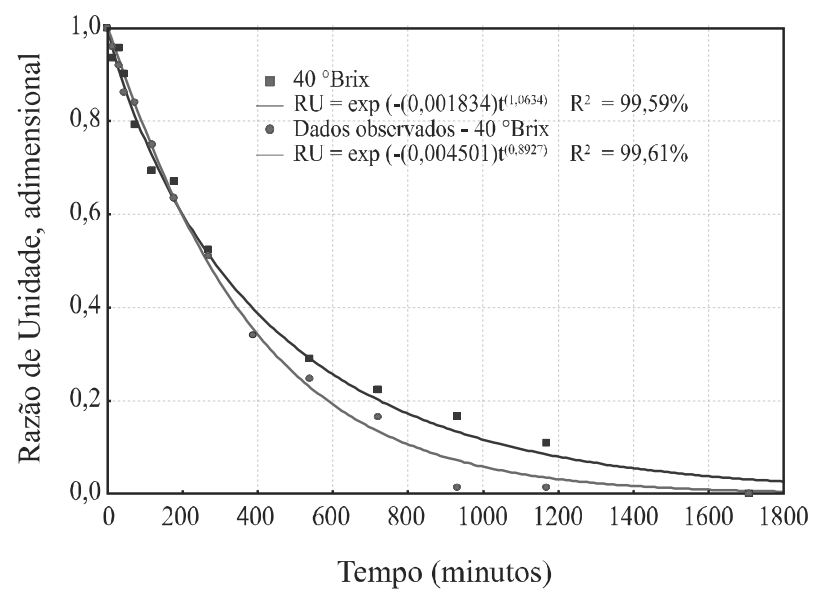

água ocorreu durante 28,5 horas de processo. Observase ainda, que a perda de água ao final da desidratação foi de, aproximadamente, 25,5 pontos percentuais para ambas as soluções. Verifica-se também que a perda de água ocorreu mais intensamente nas quatro primeiras horas de processo, assim como constatado por outros autores em estudos de desidratação osmótica (ARAÚJO, 2005; EL-AQUAR; MURR, 2003; FERNANDES, 2007; GERMER, 2011; RAGHAVARAO, 2004; RASTOGI; RODRIGUES; SILVA et al., 2008).

Quanto à perda de água, as curvas de desidratação osmótica para o produto, em ambas as soluções de sacarose, apresentaram comportamento muito semelhantes, fatos também observados por Borin et al. (2008) ao relatar sobre o efeito do prétratamento osmótico com sacarose e cloreto de sódio sobre a secagem convectiva de abóbora e por ElAquar e Murr (2003) realizando estudo semelhante com mamão formosa. Na solução a $40{ }^{\circ}$ Brix o teor de água inicial diminui de $68,5 \%$ b.u para $43 \%$ b.u, porém essa perda de água é maior, para um mesmo período de tempo, 1.710 minutos, na solução de $50{ }^{\circ}$ Brix, em que seu teor de água baixou de $68,5 \%$ b.u para $40,2 \%$ b.u. Para os dois tratamentos a maior perda de água ocorreu até os 400 minutos inicias da desidratação, seguindo a perder água mais lentamente até o equilíbrio. Corrêa et al. (2008) observaram comportamento semelhante estudando a desidratação osmótica de tomate em solução combinadas de sacarose e cloreto de sódio.

Analisando-se ainda a Figura 1, percebe-se um bom ajuste da equação de Page aos dados experimentais, para a qual se obteve um $\mathrm{R}^{2}$ acima de $99 \%$ e erro relativo médio até $8,93 \%$. Os parâmetros estimados por essa equação forneceram valores de coeficiente de difusão $(\mathrm{K}=$ 0,0044501 ) maior para o produto desidratado a $50{ }^{\circ} \mathrm{Brix}$ do que para o produto desidratado a $40{ }^{\circ}$ Brix $(\mathrm{K}=0,001834)$, que confirma o comportamento observado durante o experimento, em que se obteve o equilíbrio mais rápido para fatias de jaca submetidas em solução com maior concentração de açúcar. Dionelo et al. (2009) também observaram que fatias de abacaxi que foram desidratadas a $50{ }^{\circ} \mathrm{C}$ apresentaram maior redução de massa do que aquelas desidratadas em $40{ }^{\circ}$ Brix, em igual período de tempo. Mercali et al. (2011) no estudo da transferência de massa durante a desidratação osmótica de mirtilo, encontrou que a difusividade aumenta com o aumento da temperatura e com o aumento da concentração da solução.

A Figura 2 contém os dados experimentais de desidratação osmótica de jaca, em solução de sacarose a 40 e $50{ }^{\circ}$ Brix, respectivamente, e curvas estimadas segundo a equação de Fick com os primeiros 9 termos da série e na Tabela 2 encontram-se os valores da difusividade efetiva média, coeficiente de determinação $\left(\mathrm{R}^{2}\right)$ e erro relativo médio $(\mathrm{P})$ para o modelo difusional, sem o efeito do encolhimento.

O modelo difusional, para os primeiros 9 termos da série, sem considerar encolhimento, foi capaz de predizer a cinética de desidratação osmótica de maneira satisfatória para as duas condições de desidratação, apresentando valor de erro relativo médio aceitável, menor que $9 \%$, como pode ser observado também na Tabela 2. Provavelmente estes resultados poderiam ser melhorados, se tivesse sido considerado o fator encolhimento durante o processo de secagem. Em estudo semelhante, El-Aquar e Murr (2003), utilizando o modelo difusional, apenas quando consideraram os primeiros 15 termos da série, também sem considerar encolhimento, conseguiram resultados satisfatórios para predizer a cinética de desidratação osmótica de mamão formosa, com valor de erro relativo médio de até $10 \%$. Os 
Figura 2 - Dados experimentais de desidratação osmótica de jaca, em solução de sacarose a 40 e $50{ }^{\circ}$ Brix, respectivamente, e curvas estimadas segundo a equação de Fick com os primeiros 9 termos da série

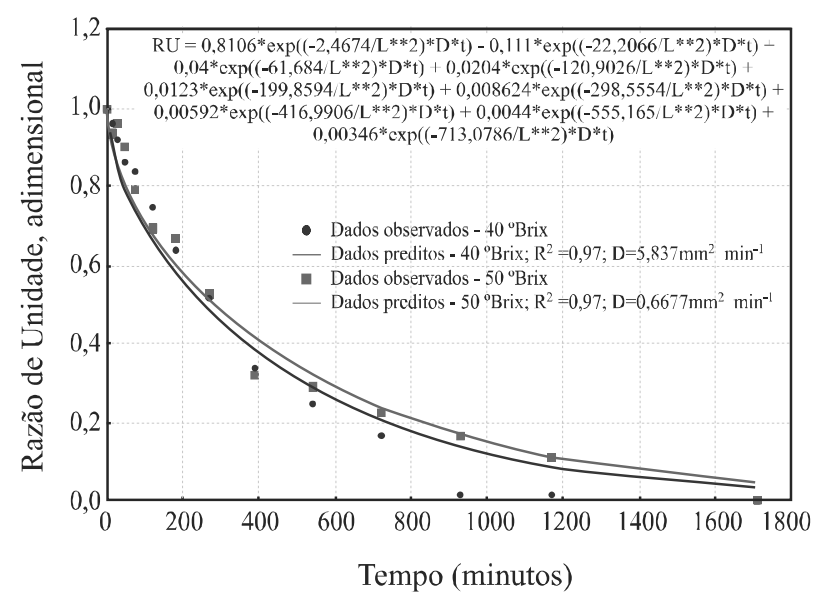

Tabela 2 - Valores da difusividade efetiva média, coeficiente de variação $\left(\mathrm{R}^{2}\right)$ e erro relativo médio $(\mathrm{P})$ para o modelo difusional, sem o efeito do encolhimento

\begin{tabular}{lcccc}
\hline Amostra & $\mathrm{D}_{\text {ef }}\left(\mathrm{mm}^{2} \mathrm{~min}^{-1}\right)$ & $\mathrm{D}_{\text {ef }}\left(\mathrm{m}^{2} \mathrm{~s}^{-1}\right)$ & $\begin{array}{c}\mathrm{R}^{2} \\
(\%)\end{array}$ & $\begin{array}{c}\mathrm{P} \\
(\%)\end{array}$ \\
\hline $\begin{array}{l}\text { Tratada a } \\
40^{\circ} \text { Brix }\end{array}$ & 0,5837 & $9,73 \times 10^{-9}$ & 97,01 & 8,93 \\
$\begin{array}{l}\text { Tratada a } \\
50^{\circ} \text { Brix }\end{array}$ & 0,6677 & $11,1 \times 10^{-9}$ & 97,42 & 6,68 \\
\hline
\end{tabular}

autores sugerem que tal fato possa ter ocorrido por não se ter considerado o encolhimento durante o processo. Foram feitos ajustes da Equação de Fick além de 9 termos, no entanto, a partir de 9 termos não ocorreram alterações significativas de melhoria no ajuste das curvas.

De acordo com a Tabela 2, observou-se que o valor da difusividade efetiva foi um pouco maior para o produto submetido à desidratação em solução de sacarose a $50^{\circ}$ Brix do que a obtida para o produto submetido à desidratação em solução de sacarose a $40{ }^{\circ}$ Brix, o que é naturalmente esperado uma vez que a perda de água na concentração de $50{ }^{\circ}$ Brix foi ligeiramente maior (DIONELO et al., 2009). Estes valores de difusividade efetiva são plausíveis de sofrer alguma alteração, com um melhor ajuste das curvas, se for considerado efeito do encolhimento, visto que o valor $\mathrm{R}^{2}$ obtido, sem esta consideração, pode ser considerado apenas razoável $\left(\mathrm{R}^{2} \approx 97 \%\right)$. Estes fatos foram também observados por El-Aquar e Murr (2003), que trabalhando com mamão formosa chegaram à mesma conclusão, de que é possível conseguir melhor ajuste se empregar a Equação de Fick, considerando o efeito do encolhimento.
Realizaram-se análises de maneira a se obter uma equação que representasse os dados de ganho de sólidos em função do tempo de desidratação, para cada solução de sacarose. As curvas apresentadas nas Figuras 3 e 4 foram as que melhor representaram os dados de ganho de sólidos. Na Figura 3 os dados foram ajustados conforme uma equação exponencial e na Figura 4 o ajuste se deu segundo uma equação polinomial de terceiro grau.

Figura 3 - Ganho de sólidos (\%) em função do tempo, durante secagem osmótica de jaca, nas concentrações de sacarose de 40 e $50^{\circ}$ Brix, usando-se uma equação exponencial

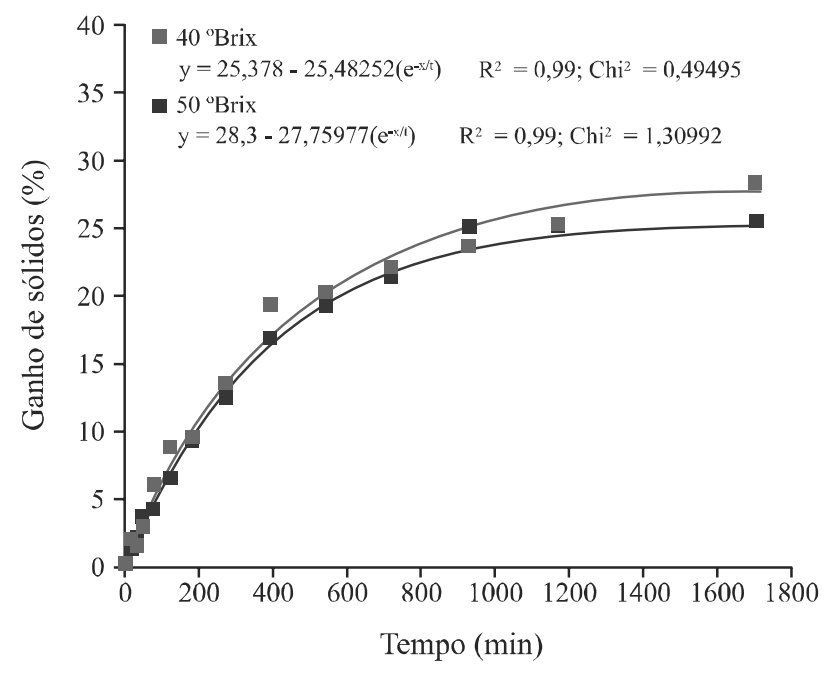

Figura 4 - Ganho de sólidos (\%) em função do tempo durante desidratação osmótica de fatias de jaca, em solução de sacarose nas concentrações de 40 e $50{ }^{\circ}$ Brix, usando-se uma equação polinomial de terceiro grau

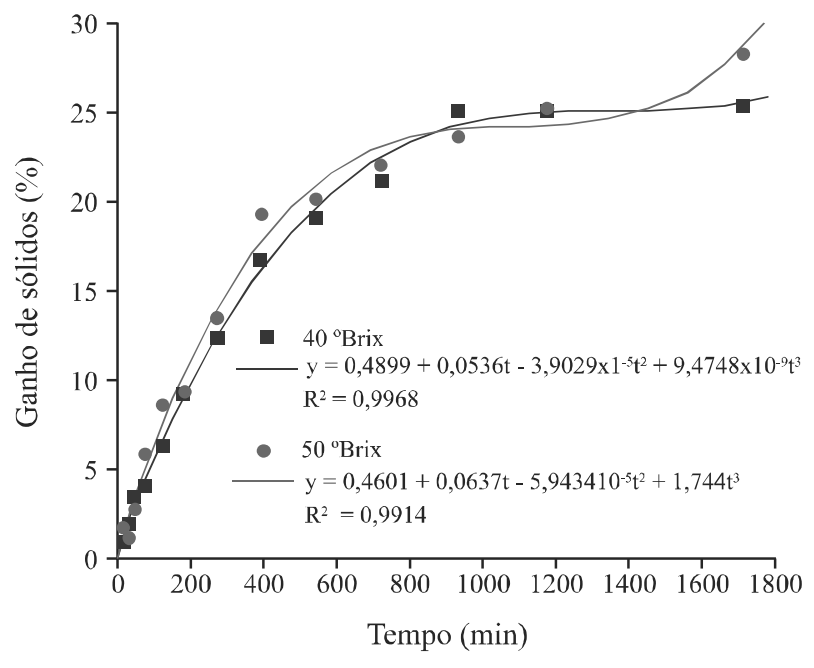


Observa-se pelas Figuras 3 e 4, que o ganho de sólidos aconteceu mais intensamente nas 3 primeiras horas de processo; logo em seguida, nota-se a tendência ao equilíbrio, ou seja, um ganho muito reduzido em um intervalo de tempo consideravelmente grande; esses fatos também foram observados por Raoult-Wack, Lenart; Guilbert (1994), El-Aquar e Murr (2003), Silva et al. (2008). No segundo caso, percebe-se que ao final do processo este ajuste apresenta certa incoerência em relação ao que se espera do fenômeno de ganho de soluto durante uma desidratação osmótica, ou seja, espera-se um comportamento que tenda ao equilíbrio (FIOREZE, 2004).

\section{CONCLUSÕES}

1. A maior perda de água, para um mesmo período de desidratação de fatias de jaca, 1.710 minutos, foi obtida com a solução osmótica a $50{ }^{\circ}$ Brix, e esta perda ocorreu com maior velocidade nos 400 minutos inicias da desidratação osmótica;

2. A incorporação de sólidos, nas fatias de jaca, ocorre em maior velocidade até os 120 minutos iniciais de processo;

3. O modelo de Page representa melhor os dados experimentais da desidratação osmótica de fatias de jaca do que o modelo difusional;

4. A difusividade efetiva média de fatias de jaca foi $0.973 \times 10^{-8} \mathrm{~m}^{2} \cdot \mathrm{s}^{-1}$ para o tratamento a $40{ }^{\circ}$ Brix e $1,11 \times 10^{-8} \mathrm{~m}^{2} . \mathrm{s}^{-1}$ para $50{ }^{\circ}$ Brix.

\section{REFERÊNCIAS}

ASSOCIATION OF OFFICIAL ANALYTICAL CHEMISTS. Official methods of analysis of the Association of Official Analytical Chemists. 18th ed. Gaithersburg, Maryland: AOAC, 2005.

ARAÚJO, E. A. F. Estudo do processo de desidratação osmótica e secagem de nectarina (Prunus pérsica). 2005. 130 f. Dissertação (Mestrado em Engenharia de Alimentos). - Departamento de Engenharia de Alimentos, Universidade Estadual de Campinas, Campinas, 2005.

BORIN, I. et al. Efeito do pré-tratamento osmótico com sacarose e cloreto de sódio sobre a secagem convectiva de abóbora. Ciência Tecnologia de Alimentos, v. 28, n. 1, p. 39-50, 2008.

CORRÊA, J. L. G. et al. Desidratação osmótica de tomate seguida de secagem. Revista Brasileira de Produtos Agroindustriais, v. 10, n. 1, p. 35-42, 2008.

CRANK, J. The mathematics of diffusion. London: Oxford University Press, 1975.
DIONELLO, R. G. et al. Desidratação osmótica de frutos de duas cultivares de abacaxi em xarope de açúcar invertido. Revista Brasileira de Engenharia Agrícola e Ambiental, v. 13, n. 5, p. 596-605, 2009.

EI-AQUAR, A. A.; MURR, F. E. X. Estudo e modelagem de cinética de desidratação osmótica do mamão formosa (Carica papaya L.). Revista Ciência e Tecnologia de Alimentos, v. 23, n. 1, p. $69-75,2003$.

FIOREZE, R. Princípios de secagem de produtos biológicos. João Pessoa: Editora Universitária, 2004. 229 p.

GERMER, S. P. M. et al. Desidratação osmótica de pêssegos em função da temperatura e concentração do xarope de sacarose. Revista Brasileira de Engenharia Agrícola e Ambiental, v. 15, n. 2, p. 161-169, 2011.

INSTITUTO ADOLFO LUTZ. Métodos químicos e físicos para análise de alimentos. 4. ed. São Paulo, 2008, 1020p. v. 1.

LANGARICA, R. V. M. Deshidratación de la pulpa de jaca (Artocarpus heterophyllus). Revista Chapingo, v.6, n. 1/2, p. 97-101, 2003.

MERCALI, G. D. et al. Estudo da transferência de massa durante a desidratação osmótica de mirtilo. Brazilian Journal of Food Technology, v. 13, n. 2, p. 91-97, 2011.

QUEIROZ, V. A. V. et al. Mecanismos de transferência de massa na desidratação osmótica de goiaba em soluções de sacarose, sucralose e açúcar invertido. Engenharia Agrícola v. 30, n. 4, p. 715-725, 2010. Disponível em: < http://www.scielo.br/scielo. php? script=sci_arttext \&pid=S0100-69162010000400015\&lng $=$ em\&nrm=iso $>$. Acesso em: 06 fev. 2011.

RASTOGI, N. K.; RAGHAVARAO, K. S. M. S. Mass transfer during osmotic dehydration of pineapple: considering Fickian diffusion in cubical configuration. Lebensmittel-Wissenschaft und Technologie, v. 37, n. 1, p. 43-47, 2004.

RODRIGUES, S.; FERNADES, F. A. N. Dehydration of melons in a ternary system followed by air-drying. Journal of Food Engineering, v. 80, n. 2, p. 678-687, 2007.

RAOULT-WACK, A. L.; LENART, A.; GUILBERT, S. Recent advances in the osmotic dehydration of foods. Trends in Food Science e Technology, n. 5, p. 255-260, 1994.

SILVA, A. S. et al. Desidratação e efeito de pré-tratamentos no extrato seco do pimentão verde. Revista Brasileira de Produtos Agroindustriais, v. 10, n. 1, p. 27-34, 2008.

SILVEIRA, P. L. Estudo da elaboração de passas de polpa, aproveitamento dos caroços e resíduos da jaca (Artocarpus heterophyllus). 2002. 70 f. Dissertação (Mestrado em Engenharia de Alimentos) - Departamento de Engenharia de Alimentos, Universidade Federal da Paraíba, João Pessoa, 2002.

TORREGGIANI, D.; BERTOLO, G. Osmotic pre-treatments in fruit processing: chemical, physical and structural effects. Journal of Food Engineering, v. 49, n. 2, p. 247-253, 2001. 